\title{
Hypoxia-Induced Mesenchymal Stromal Cells Exhibit an Enhanced Therapeutic Effect on Radiation-Induced Lung Injury in Mice due to an Increased Proliferation Potential and Enhanced Antioxidant Ability
}

\author{
Bailong Lia Cheng Lib Mo Zhu ${ }^{\mathrm{b}} \quad$ Youjun Zhang ${ }^{\mathrm{c}} \quad$ Jicong Du ${ }^{\mathrm{a}} \quad$ Yang Xu \\ Bin Liu ${ }^{a} \quad \mathrm{Fu} \mathrm{GaO}^{\mathrm{a}}$ Hu Liu ${ }^{\mathrm{a}}$ Jianming Cai ${ }^{\mathrm{a}}$ Yanyong Yang ${ }^{\mathrm{a}}$ \\ aDepartment of Radiation Medicine, Faculty of Naval Medicine, Second Military Medical University, \\ Shanghai, ${ }^{b} 1$ st cadet battalion of naval medicine department, Second Military Medical University, \\ Shanghai, 'Department of Naval Health Service and Medical Equipment, Faculty of Medicine, Second \\ Military Medical University, Shanghai, China
}

\section{Key Words}

Radiation-induced lung injury - Mesenchymal stromal cells - Reactive oxygen species • Hypoxia-inducible factor- 1 - Hypoxia $・$ EdU assay

\begin{abstract}
Background/Aims: Radiation therapy is an important treatment for thoracic cancer; however, side effects accompanied with radiotherapy lead to limited tumor control and a decline in patient quality of life. Among these side effects, radiation-induced lung injury (RILI) is the most serious and common. Hence, an effective remedy for RILI is needed. Mesenchymal stromal cells (MSCs) are multipotent adult stem cells that have been demonstrated to be an effective treatment in some disease caused by tissue damage. However, unlike other injuries, RILI received limited therapeutic effects from implanted MSCs due to local hypoxia and extensive reactive oxygen species (ROS) in irradiated lungs. Since the poor survival of MSCs is primarily due to hypoxia and ROS generation, we hypothesize that persistent and adaptive hypoxia treatment induces enhanced resistance to hypoxic stress in implanted MSC. The aim of this study is to investigate whether persistent and adaptive hypoxia treatment of bmMSCs prior to their transplantation in injured mice enhanced survival and improved curative effects in RILI. Methods: Primary bmMSCs were obtained from the marrow of sixweek-old male C57BL6/J mice and were cultured either under normoxic conditions $\left(21 \% \mathrm{O}_{2}\right)$ or hypoxic conditions $\left(2.5 \% \mathrm{O}_{2}\right)$. Mice were injected with normoxia/hypoxia MSCs after thoracic irradiation (20 Gy). The therapeutic effects of MSCs on RILI were assessed by pathological examinations that included $H \& E$ staining, Masson staining and $\alpha-S M A$ staining; meanwhile, B. Li, C. Li, M. Zhu and Y. Zhang contributed equally to this work.
\end{abstract}

Yanyong Yang, Jianming Cai and $\mathrm{Hu}$ Liu
Department of Radiation Medicine, Faculty of Naval Medicine,

Second Military Medical University, Shanghai, (China)

E-Mail yyyang2010@163.com, cjm882003@163.com, gzsassliuhu@163.com 
inflammatory factors were measured using an ELISA. The morphology of MSCs in vitro was recorded using a microscope and identified by flow cytometry, cell viability was measured using the CCK-8 assay, the potential for proliferation was detected by the EdU assay, and ROS levels were measured using a ROS fluorogenic probe. In addition, HIF-1 $\alpha$ and several survival pathway proteins (Akt, p-Akt, Caspase-3) were also detected by western blotting. Results: Implanted MSCs alleviated both early radiation-induced pneumonia and late pulmonary fibrosis. However, hypoxia MSCs displayed a more pronounced therapeutic effect compared to normoxia MSCs. Compared to normoxia MSCs, the hypoxia MSCs demonstrated greater cell viability, an enhanced proliferation potential, decreased ROS levels and increased resistance to hypoxia and ROS stress. In addition, hypoxia MSCs achieved higher activation levels of HIF$1 \alpha$ and Akt, and HIF-1 $\alpha$ played a critical role in the development of resistance. Conclusion: Hypoxia enhances the therapeutic effect of mesenchymal stromal cells on radiation-induced lung injury by promoting MSC proliferation and improving their antioxidant ability, mediated by HIF- $1 \alpha$.

\section{Introduction}

Radiation therapy is an important treatment for thoracic cancers, such as lung cancer, breast cancer, esophageal cancer, lymphoma and thymoma [1]; however, side effects from radiotherapy usually limit tumor control and lower patient quality of life. Among the side effects, radiation-induced lung injury (RILI) is the most serious and common disease. It is estimated that the clinical incidence of RILI ranges from $5 \%$ to $10 \%$, which to some degree leads to thoracoscopic radiotherapy failure [2,3]. Therefore, an effective treatment strategy for RILI is urgently required. Development of RILI is a complex and continuous process, which is pathologically divided into two phases: the early pneumonitis phase and the later fibrosis phase [4]. Considerable inflammation in early pneumonitis and restricted breathing in later fibrosis make it difficult to treat RILI. Steroids have been commonly used for RILI treatment; however, their side effects, including osteoporosis and immunosuppression, limit their application [5].

Mesenchymal stromal cells (MSCs) are a type of multipotent adult stem cell that can be isolated from several tissues such as bone marrow (bmMSCs) and adipose tissues (adMSCs) $[6,7]$. Self-renewal and multilineage differentiation are the primary characteristics of MSCs $[8,9]$. bmMSCs in particular have been demonstrated to be an effective treatment in certain diseases caused by tissue damage, including ischemic heart failure [10], hind limb ischemia [11], liver, skin and gut damages [12-15]. The abovementioned therapeutic effects suggest that MSCs may be a valid treatment option for RILI. Indeed, some researchers have made attempts to investigate this hypothesis [16]. However, unlike the successful results in other tissues, after 24 hours of transplantation into the injured lungs, engrafted MSCs decreased dramatically, with an engraftment between $0.01 \%$ and $0.1 \%$ due to extensive oxidative stress and local hypoxia $[17,18]$. Therefore, the therapeutic effect of MSCs may be conditionally limited.

Since hypoxia and generated ROS contribute to the poor survivability of MSCs, we hypothesize that persistent and adaptive hypoxia treatment may induce enhanced resistance to hypoxia pressure in MSCs. Moreover, adaptive response to hypoxia is known to upregulate hypoxia-inducible factor-1 (HIF-1 $\alpha$ ) which is confirmed to promote hypoxia tolerance.

The aim of this study is to investigate whether persistent and adaptive hypoxia treatment of bmMSCs prior to their transplantation in injured mice can enhance their survival under hypoxia and promote curative effects in RILI. 


\section{Cellular Physiology Cell Physiol Biochem 2017;44:1295-1310

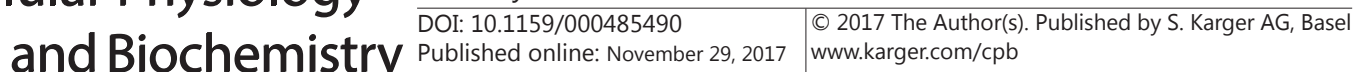

Li et al.: Hypoxia Enhances the Therapeutic Effect of Mscs on RILI

\section{Materials and Methods}

\section{MSC isolation and culture}

MSCs-also known as bmMSCs-were obtained from the marrow of six-week-old male C57BL6/J mice. First, bilateral femurs of mice were removed by isolating attached connective tissue. Intact femurs were flushed out using a syringe in order to obtain as much marrow as possible. One group of isolated MSCs was cultured at $37^{\circ} \mathrm{C}$ under $5 \% \mathrm{CO}_{2}, 21 \% \mathrm{O}_{2}$ in a humidified tissue culture incubator, and another group of MSCs was cultured in a hypoxic environment $\left(2.5 \% \mathrm{O}_{2}\right) .5$ days later, suspended cells were removed and the remaining adherent cells were continuously cultured in culture medium (DMEM)/F12 containing 10\% inactivated fetal bovine serum (FBS), $100 \mathrm{U} / \mathrm{mL}$ penicillin, and $100 \mathrm{~g} / \mathrm{mL}$ streptomycin (GIBCO, Carlsbad, CA, USA). Finally, the third passage MSCs were harvested for subsequent experiments [19].

\section{Hypoxia culture of MSCS}

Primary MSCs were cultured under hypoxic conditions i.e., 2.5\% $\mathrm{O}_{2}$ and $5 \% \mathrm{CO}_{2}$ in a hypoxia gas chamber. MSCs were cultured in culture medium (DMEM)/F12 containing 10\% inactivated fetal bovine serum (FBS), $100 \mathrm{U} / \mathrm{mL}$ penicillin, and $100 \mathrm{~g} / \mathrm{mL}$ streptomycin (GIBCO, Carlsbad, CA, USA). Suspension cells were intermittently removed, and the final third passage of adherent cells were harvested.

\section{Cell viability assessment and Clonogenic survival}

Cell viability was determined by the calorimetric CCK-8 assay (Cell Counting Kit-8; Dojindo, Kumamoto, Japan). Adherent MSCs were suspended and planked into 96-well plates at a cell density of $5 \times 10^{3}$ cells. Twelve hours later, the viability of adherent MSCs was detected by the CCK-8 assay. The colony-forming assay was performed as previously described [20].

\section{Establishment of radiation-induced lung injury model of mice}

Following anesthesia, mice were immobilized in a circumscribed box with only the lungs of mice exposed to irradiation, whereas other parts of the box were shielded by lead. Lungs of mice received irradiation at a total dose of $20 \mathrm{~Gy}$ and a dose rate of $1 \mathrm{~Gy} / \mathrm{min}$. The irradiation source was ${ }^{60} \mathrm{Co}$ from the radiation center (Faculty of Naval Medicine, Second Military Medical University, China) [21, 22].

\section{Histopathology and immunohistochemistry}

Lungs were inflated with 10\% formalin (Sigma-Aldrich), paraffin-embedded and sectioned (5 micron) at the Pathology center of Changhai Hospital. Sections were stained with hematoxylin and eosin, Masson's Trichrome stain and the $\alpha$-SMA antibody (1:200; Abcam).

\section{Identification of MSCs}

In order to confirm purity and identify the source of MSCs, we marked cells with rabbit monoclonal anti-mice CD34, CD90, CD45 and CD105 and identified them using flow cytometry. Accordingly, cells that were negative for CD45 and CD34 and positive for CD90 and CD105 were identified as pure MSCs [23].

\section{Cytokine and chemokine assays}

Peripheral blood was collected following enucleation of the eyeball, centrifuged at $2520 \times \mathrm{g}$ and then stored at $4^{\circ} \mathrm{C}$ for $10 \mathrm{~min}$. Serum was used for ELISA according to the manufacturer's instructions.

\section{Western blot analysis}

MSCs were collected after treatment. Next, cells were resuspended in PBS and washed 3 times. Following collection in extraction buffer (1\% Triton X-100, 0.5\% sodium deoxycholate, $20 \mathrm{mM}$ Tris- $\mathrm{HCl}, \mathrm{pH}$ 7.5, 12 mM-glycero-phosphate, $150 \mathrm{mM} \mathrm{NaCl}, 5 \mathrm{mM}$ EGTA, $10 \mathrm{mM} \mathrm{NaF,} 3 \mathrm{mM}$ dithiothreitol, $1 \mathrm{mM}$ sodium orthovanadate, $1 \mathrm{mM}$ phenylmethylsulfonyl fluoride, $20 \mathrm{~g} / \mathrm{ml}$ aprotinin), cells were incubated on ice for $3 \times 10$ min, and the lysate was centrifuged $\left(12,000 \times \mathrm{g}\right.$ for 15 minutes at $\left.4^{\circ} \mathrm{C}\right)$ in order to obtain the supernatant containing protein. Equal amounts of proteins were separated on a 10\% SDS-PAGE gel and transferred to nitrocellulose membranes. 5\% low-fat milk was used to block membranes for 2 hours, following which the membranes were washed with TBST 3 times for $10 \mathrm{~min}$. Membranes were probed overnight at $4^{\circ} \mathrm{C}$ with antibodies recognizing the following antigens: Akt1 (1:1000), p-Akt (473) (1:1000), $\beta$-actin (1:1000), HIF- 


\section{Cellular Physiology Cell Physiol Biochem 2017;44:1295-1310 and BiOChemistry \begin{tabular}{l|l} 
DOI: $10.1159 / 000485490$ & $\begin{array}{l}\text { C } 2017 \text { The Author(s). Published by S. Karger AG, Basel } \\
\text { www.karger.com/cpb }\end{array}$
\end{tabular}}

Li et al.: Hypoxia Enhances the Therapeutic Effect of Mscs on RILI

$1 \alpha$ (1:1000), Caspase-3 (1:1000); All antibodies were obtained from Cell-signal corporation. The antibodyantigen complex was detected using horseradish peroxidase-conjugated secondary antibody. Peroxidase labeling was visualized using enhanced chemiluminescence labeling of the ECL Western blotting detection system (Thermo, USA).

\section{Real-time quantitative RT-PCR}

Expression levels of RNA were quantitated by real-time PCR. We isolated

total cellular RNA from lung tissue disrupted by Polytron using TRIzol (Invitrogen, Carlsbad, CA, USA). The SYBR Green assay and the ABI Prism 7900HT Sequence Detection System (Applied Biosystems, Rotkreuz, Switzerland) were used for real-time quantitation of the RNA. The primer used for $\alpha$-SMA was as follows: forward 5'-GCCAA GCACT GTCAG GAATC C-3', reverse 5'-CACAA TGGAT GGGAA AACAG CC-3'

\section{Measurement of intracellular GSH, SOD and ROS levels}

GSH and SOD levels of MSCs were measured using the GSH and SOD assay kits, respectively (Cat. No. S0053, S0109; Beyotime; China). Intracellular ROS was detected using the Reactive Oxygen Species Fluorogenic Probe (Cat. No. S0033; Beyotime; China) and was observed using fluorescence microscopy.

Statistical Analysis

All values were expressed as the mean \pm SD. One-way ANOVA analysis was carried out to calculate the difference among the groups. Between two groups, variance was determined using Student's t-test. Significance was defined as a value of $P<0.05$.

\section{Results}

Culture and Identification of MSCs

Primary bone marrow cells from mice femurs were equally divided into two groups: one group was incubated under normoxic conditions with $21 \% \mathrm{O}_{2}$, and another group was cultured under hypoxic conditions with $2.5 \% \mathrm{O}_{2}$. Cells morphology was recorded for one week using a microscope. Until the third passage, adherent cells were harvested and identified by flow cytometry. With intermittent removal of suspension cells, final adherent cells were retained and proliferated. On the third day, we observed several spindle-shaped fibroblast-like cells, and on the seventh day, their numbers evidently increased. In contrast to normoxic conditions $\left(21 \% \mathrm{O}_{2}\right)$, hypoxic conditions $\left(2.5 \% \mathrm{O}_{2}\right)$ promoted MSC proliferation. The density of adherent cells under hypoxic condition, especially on the seventh day, was significantly higher (Fig. 1A, B; $P<0.01$ ). Using flow cytometry, the normoxia MSCs were marked as CD45- and CD34-negative and CD105- and CD90-positive (the percentage of CD105- and CD90-positive cells was $72.59 \pm 8.55 \%$ and $51.73 \pm 3.59 \%$, respectively). In contrast, the hypoxia MSCs demonstrated an elevated percentage of CD34-positive cells $(13.20 \pm 5.43 \%$ vs. $2.25 \pm 0.90 \%, P<0.05)$ and a decreased percentage of CD90-positive cells $(26.83 \pm 5.77 \%$ vs. $51.73 \pm 3.59 \%$, respectively; $P<0.01$ ) (Fig. 1 C, D).

Comparison between therapeutic effects of normoxia MSCs and hypoxia MSCs on RILI

Two hours after the lungs of mice received 20 Gy irradiation, normoxia MSCs and hypoxia MSCs were injected at a concentration of $2 \times 10^{6}$ cells $/ \mathrm{ml}$ using a tail intravenous injection. At the $7^{\text {th }}, 21^{\text {st }}$ and $42^{\text {nd }}$ days, mice lungs were subjected to pathological detection by H\&E staining (Fig. 2A, F) and the amount of lung collagen visualized and assessed by Masson's trichrome staining (Fig. 2B, G). The extent of fibrosis was estimated by $\alpha$-SMA IHC (Fig. 2C, H), western blotting (Fig. 2D) and RT-PCR (Fig. 2E). Simultaneously, at 1, 3, 6 weeks after irradiation, serum samples of mice were collected to detect TNF- $\alpha$, TGF- $\beta$ and INF- $\gamma$ levels (Fig. 2I-K). Following exposure to irradiation, the lungs of mice showed exudation of red blood cells, infiltration of inflammatory cells and collapsed alveoli in the first week. With the progress of RILI, the extracellular matrix increased during the period between the third and the sixth week. Both groups of implanted MSCs remitted early pneumonia and mitigated 
Fig. 1. The mor- A phology feature of MSC and identification by flow cytometry: Primary bmMSCs from mice were divided into two groups one was cultured under normoxia and another was under hypoxia condition. All the MSCs were observed every day and photographed at the third and seventh day (A). Each group of MSCs was counted for weeks (B). Mag-

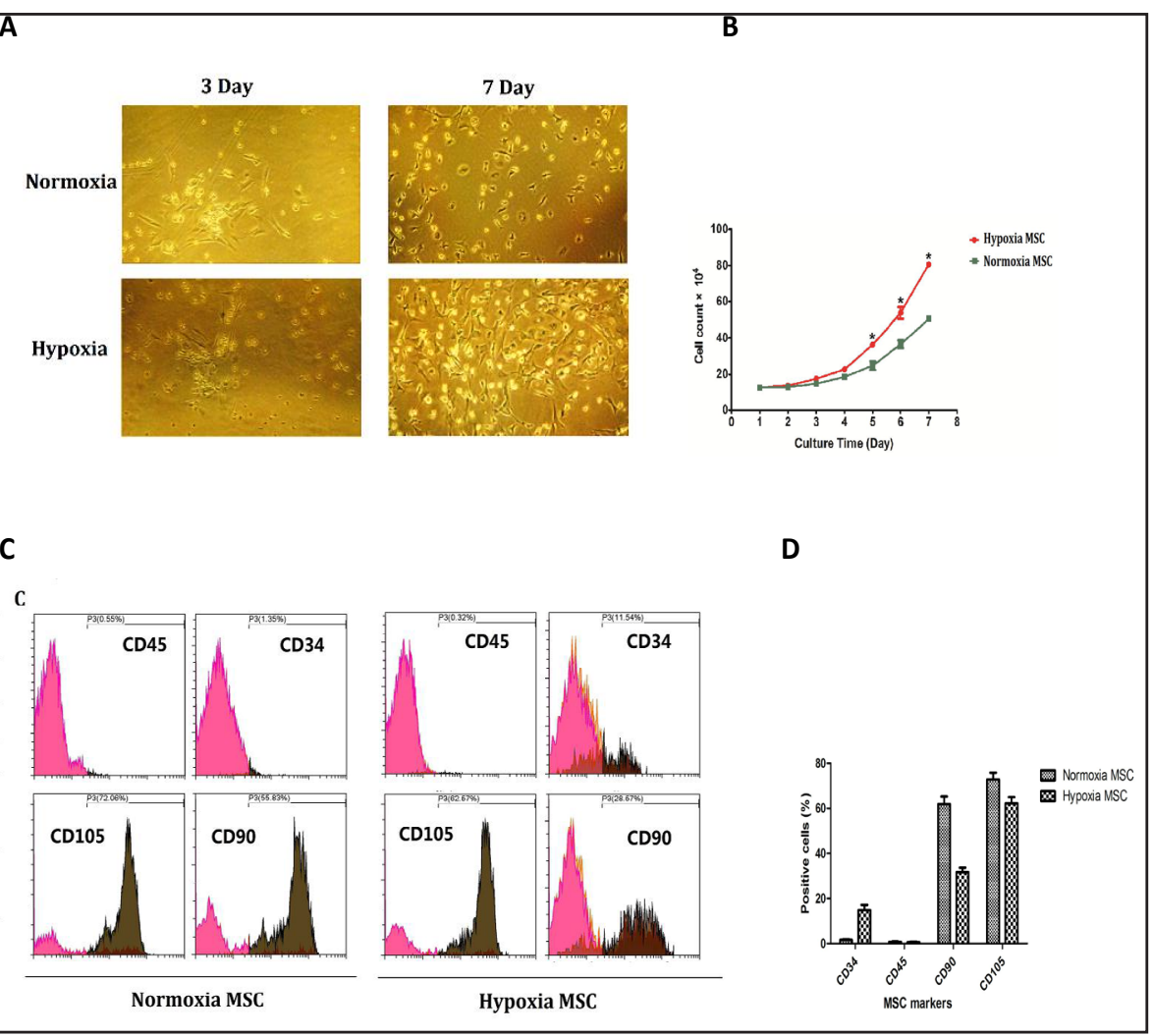
nification x 100 .

Until the third passage adherence cells were harvested to make identification by flow cytometry (C, D). Data were presented as mean $\pm \mathrm{SD}(\mathrm{n}=3)$. ${ }^{*} \mathrm{P}<0.05$ as compared with control.

late pulmonary fibrosis. However, hypoxia MSCs demonstrated greater significant effects compared to normoxia MSCs, especially in the reduction of extracellular matrix.

\section{Hypoxia MSCs reside for longer in radiation-injured lungs}

Although MSCs demonstrated an in vitro therapeutic effect in RILI, the in vivo fates of implanted MSCs still needed to be determined. In order to trace the fates of the MSCs, we established GFP-marked MSCs by transfecting adenovirus vectors carrying the GFP gene. Next, the GFP-MSCs were cultured under normoxia or hypoxic conditions until third passage. A total of $2 \times 10^{6}$ GFP-MSCs were injected into irradiated mice by caudal vein injection. At $6 \mathrm{~h}, 12 \mathrm{~h}, 24 \mathrm{~h}, 48 \mathrm{~h}, 72 \mathrm{~h}$ and day 7 post-injection, the lungs of mice were examined for fluorescence. Our results demonstrated that normoxia MSCs and hypoxia MSCs emerged at $6 \mathrm{~h}$ after injection and peaked at $12 \mathrm{~h}$. However, the number of implanted normoxia MSCs decreased at 24 hours, and by $48 \mathrm{~h}$, there were no observable MSCs. In contrast, the number of hypoxia MSCs peaked at $24 \mathrm{~h}$ and was sustained until $72 \mathrm{~h}$. This result demonstrated a longer residence of hypoxia MSCs in radiation-injury lungs (Fig. 3).

Hypoxia MSCs demonstrated increased cell viability and enhanced proliferation potential

Since hypoxia MSCs were therapeutically more effective in RILI compared to normoxia MSCs, we investigated whether this enhanced effect was associated with increased cell viability and proliferation. Cell viability was tested by the CCK- 8 assay. Following addition of the CCK-8 counting reagent, we recorded values at $30 \mathrm{~min}, 1 \mathrm{~h}, 1.5 \mathrm{~h}$, and $2 \mathrm{~h}$ using a microplate reader. Hypoxia MSCs incubated with CCK-8 counting reagent began to show significantly higher viability compared to normoxia MSCs beginning at $1.5 \mathrm{~h}$ (Fig. 4A; OD value: $1.34 \pm 0.09 \mathrm{VS} .1 .63 \pm 0.14$, respectively; $P<0.05$ ). The clone formation assay was used to assess cell proliferation potential. The same amount of MSCs were cultured under normoxic 


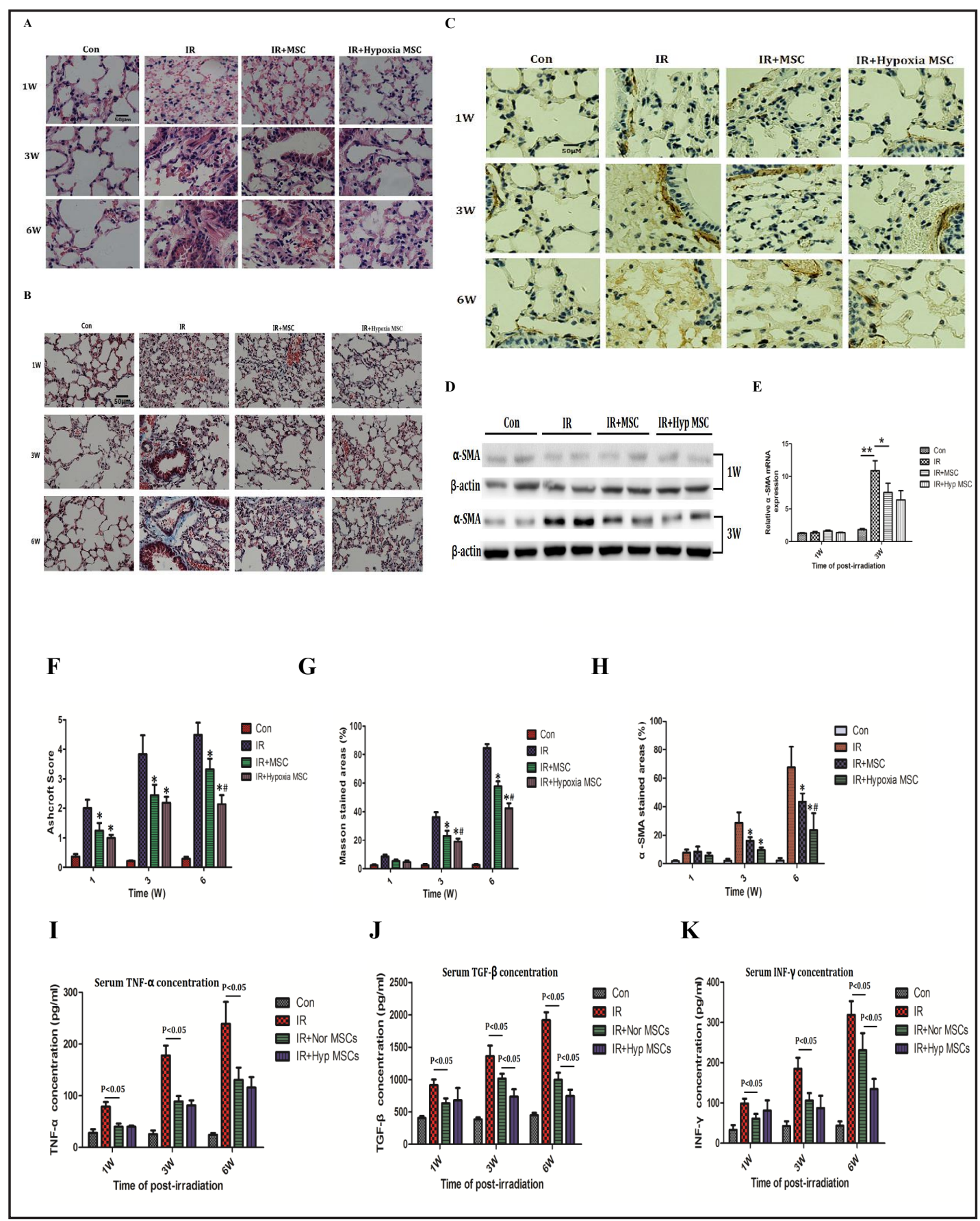

Fig. 2. Comparison of therapeutic effect on RILI between normoxia MSCs and hypoxia MSCs: Two hours after the lungs of mice have received irradiation of 20Gy, we implanted normoxia MSCs and hypoxia MSCs by tail vein injection, respectively. At $7^{\text {th }}, 21^{\text {st }}$ and $42^{\text {nd }}$ day the irradiated lungs of mice were taken to make pathological comparison by HE staining (A), assess amount of lung collagen visualized by Masson's trichrome staining (B) and $\alpha$-SMA staining (C). Western blotting and RT-PCR were conducted to confirm the expression of $\alpha$-SMA in lung tissues at one and three week after irradiation (D, E; $n=4$ ). Quantitative assessment of HE stain, Masson Trichrome stain and $\alpha$-SMA staining were performed by Ashcroft score (F), Masson stained areas (G) and $\alpha$-SMA stained areas (H). Simultaneously at 1, 3, 6 weeks after irradiation the serums of mice were collected to detect TNF- $\alpha$, TGF- $\beta$ and INF- $\gamma$ levels (I-K). Data were presented as mean \pm SD $(\mathrm{n}=5) .{ }^{*} \mathrm{P}<0.05$ vs IR group; ${ }^{\#} \mathrm{P}<0.05$ vs IR+MSC group; ${ }^{* *} \mathrm{P}<0.01$; Magnification $\times 200$. Scale bar, $50 \mu \mathrm{m}$.

\section{KARGER}


Fig. 3. MSCs home to radiationinjury lungs: Two hours after radiation, mice were injected a total of $2 \times 10^{6}$ GFP-labeled normoxia MSCs or hypoxia MSCs (green) by caudal vein. At $6 \mathrm{~h}, 12 \mathrm{~h}, 24 \mathrm{~h}$, $48 \mathrm{~h}, 72 \mathrm{~h}$ and day 7 post-injection, the frozen section of mice lungs were fluorescence analyzed. Magnification×100 (A); quantified analysis was performed as counting GFP-labeled cells per visual field and recording 10 fields per section (B). Data were presented as mean \pm SD (n $=3$ ). ${ }^{*} \mathrm{P}<0.05$ vs normixa MSCs group.

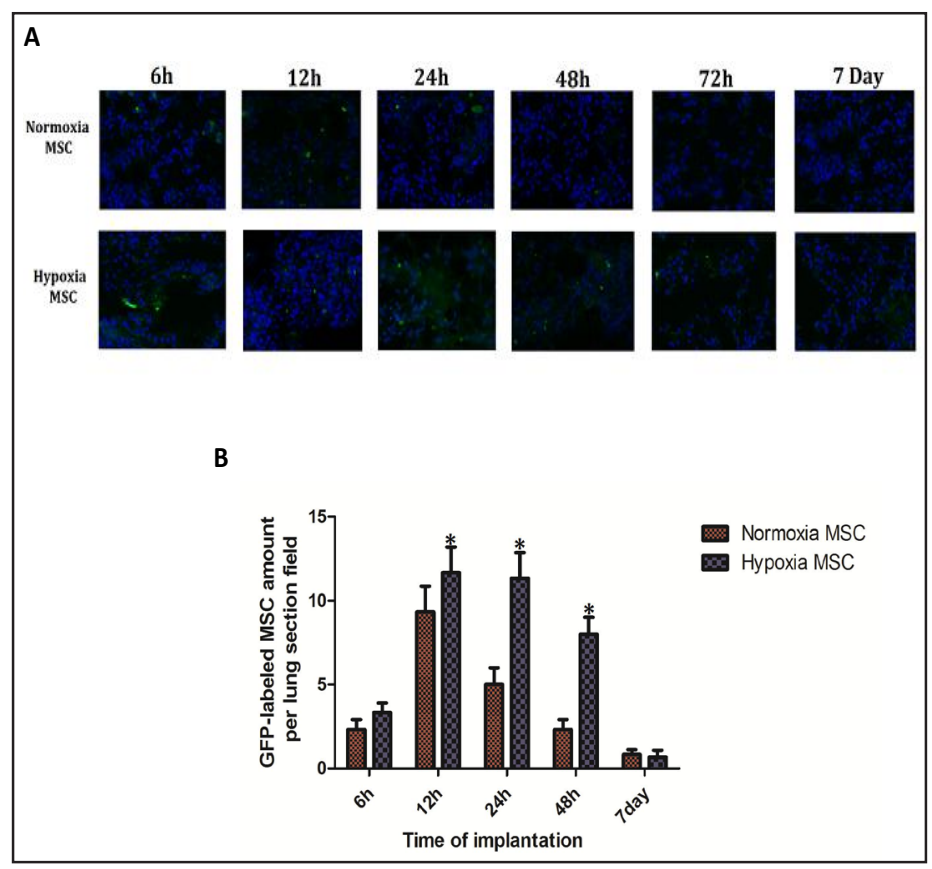

and hypoxic conditions. On the fifth and seventh days, hypoxia MSCs were counted, and a greater number of clones were observed compared to the number observed for the normoxia MSCs, thereby indicating the enhanced proliferation potential of hypoxia MSCs (Fig. 4B, C; number of clones on day 10: $315 \pm 16.71$ VS $576 \pm 63.03 ; P<0.01$ ). To further confirm the result of the proliferation assay, we performed the EdU assay which fluorescently marks replicated DNA chains in order to reflect cell division. Using fluorescence microscopy, more positive stains (green) were observed in hypoxia MSCs compared to those observed for the normoxia MSCs, thereby indicating quicker DNA synthesis and enhanced proliferation (Fig. 4D, E; ratio of EdU-positive cells in normoxia and hypoxia MSCs: $36.16 \pm 5.62 \%$ VS 69.23 $\pm 6.07 \%$, respectively; $P<0.01$ ).

\section{Hypoxia MSCs had decreased levels of ROS and increased antioxidant ability}

Extensive ROS generation enormously limits the survival and retention of implanted MSCs in radiation-damaged lungs [24]. We investigated whether ROS generation and antioxidant abilities of hypoxia MSCs are different from normoxia MSCs. Using the Reactive Oxygen Species Assay Kit, the levels of intracellular ROS and antioxidant ability were detected by measuring the content of GSH and SOD, which are commonly considered the primary antioxidases. Our results demonstrated that hypoxia MSCs showed lower fluorescence intensity compared to normoxia MSCs, thereby indicating less ROS generation in hypoxia MSCs (Fig. 5A). Levels of GSH and SOD increased with cell growth, and on the fifth day, the levels in hypoxia MSCs began to significantly exceed those in the normoxia MSCs, demonstrating that hypoxia induced an increase in antioxidant activity (Fig. 5B, C).

\section{Hypoxia MSCs acquired greater resistance to hypoxia and ROS stress compared to normoxia} MSCS

The poor survival and retention of implanted MSCs in radiation-damaged lungs is due to local hypoxia and extensive ROS . Since hypoxia MSCs demonstrated increased levels of antioxidants (GSH, SOD) and decreased generation of intracellular ROS compared to levels in normoxia MSCs, we investigated whether hypoxia MSCs demonstrated enhanced resistance to external hypoxia and ROS stress. We first induced hypoxia tolerance in MSCs by culturing primary bmMSCs under hypoxic conditions $(2.5 \%)$ for a few weeks. To induce hypoxia stress for hypoxia MSCs, we lowered the oxygen concentration to 1\%. Hypoxia MSCs and normoxia 
Fig. 4. Hypoxia MSCs gained increased cell viability and enhanced potential of proliferation: The third passage normoxia MSCs and hypoxia MSCs were harvested to assess the cells viability by CCK-8 assay (A) and test potential of proliferation by clone formation (B, C). Primary MSCs were cultured under normoxia and hypoxia conditions respectively, and on the seventh day the Edu assay was performed to assess the proliferation of MSCs. The reaction revealed EdU staining (green) and cell nuclei were stained with Hoechst 33342 (blue). The images were representative of the obtained results (D).The percentage of Edu positive cells were quantified (E). Data were presented as mean $\pm \mathrm{SD}(\mathrm{n}=3) .{ }^{*} \mathrm{P}<0.01$ as compared with control.

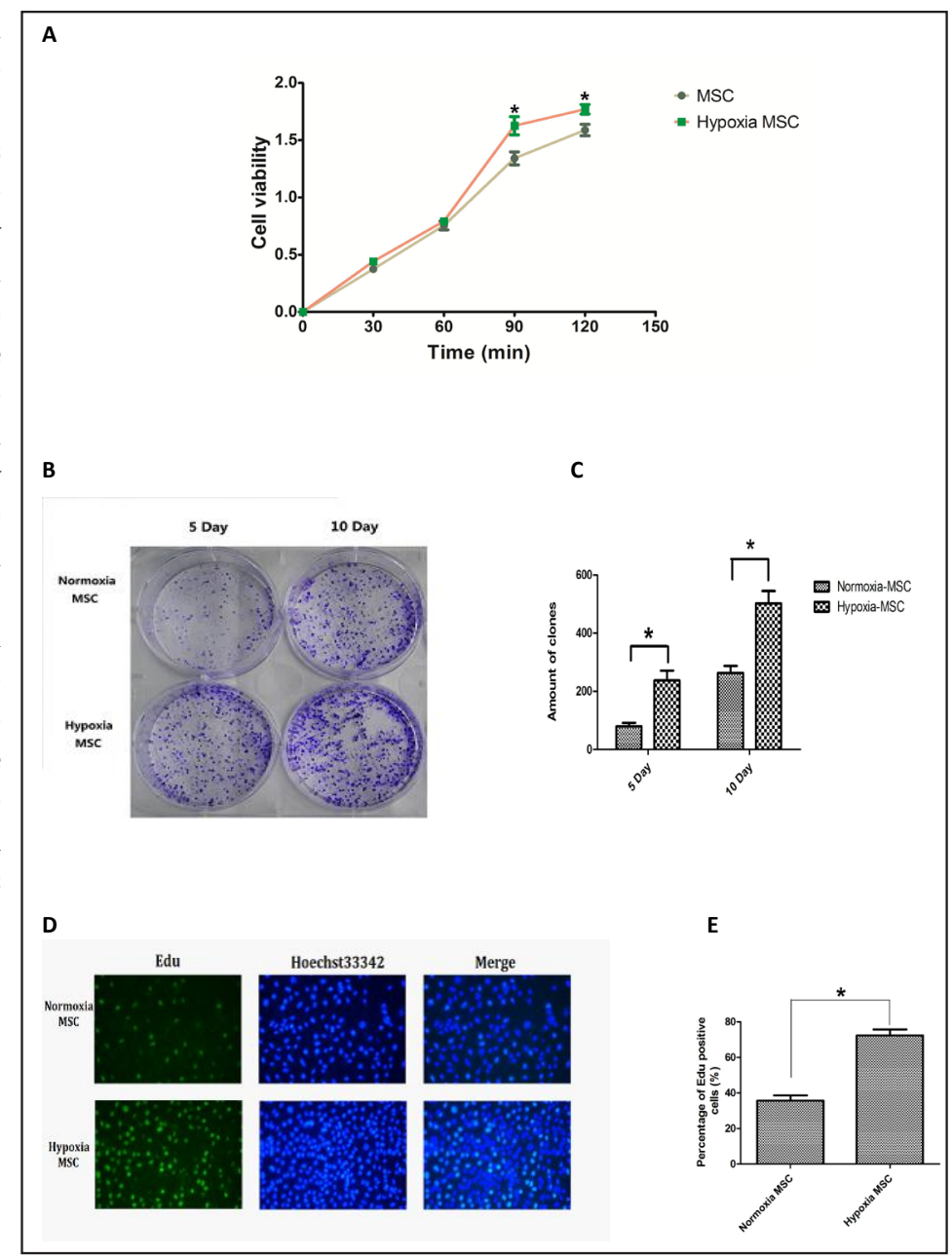

MSCs were cultured under hypoxic conditions $\left(1 \% \mathrm{O}_{2}\right)$, and their viability was detected at 1 $\mathrm{h}, 4 \mathrm{~h}, 8 \mathrm{~h}, 12 \mathrm{~h}$, and $24 \mathrm{~h}$ by the CCK- 8 assay. The results demonstrated that the viability of normoxia MSCs decreased in a time-dependent manner. In contrast, there was no significant reduction in viability in hypoxia MSCs with the passage of time (Fig. 6A, $P<0.05$ ). ROS stress was induced using $\mathrm{H}_{2} \mathrm{O}_{2}$. Both the hypoxia MSCs and normoxia MSCs were treated with $\mathrm{H}_{2} \mathrm{O}_{2}(100 \mu \mathrm{M})$ for $12 \mathrm{~h}$ and cells were then harvested to detect the cell apoptosis rate by flow cytometry. The results demonstrated that $\mathrm{H}_{2} \mathrm{O}_{2}$ induced apoptosis of MSCs; however, hypoxia MSCs showed significantly lower apoptosis rates compared to those of normoxia MSCs $(12.23 \pm 2.64 \%$ VS $20.17 \pm 4.15 \%$, respectively; $P<0.05)$, which indicated that hypoxia MSCs acquired enhanced resistance to ROS stress (Fig. 6B).

HIF-1 was involved in the resistance of hypoxia MSCs to hypoxia stress

Hypoxia-inducible factor-1 (HIF-1) was confirmed to be the critical response factor to hypoxia stress and was upregulated by hypoxia [25]. Hence, we investigated whether HIF-1 plays a role in enhancing the resistance of hypoxia MSCs to hypoxia stress. We detected the expression of HIF- $1 \alpha$ and several survival pathway proteins including Akt, p-Akt (S473), and caspase-3 by western blotting. As shown in Fig. 7A and 7B, the basic expression levels of Akt, p-Akt (S473) and HIF-1 $\alpha$ were higher in hypoxia MSCs compared to those in normoxia MSCs. Under hypoxic $\left(1 \% \mathrm{O}_{2}\right)$ stimulation, normoxia MSCs acquired evidently upregulated expression levels of p-Akt (S473), HIF-1 $\alpha$ and Caspase-3 at 8 hours; however, the hypoxia MSCs showed fewer alterations in the levels of these proteins, which indicated that hypoxia 
A
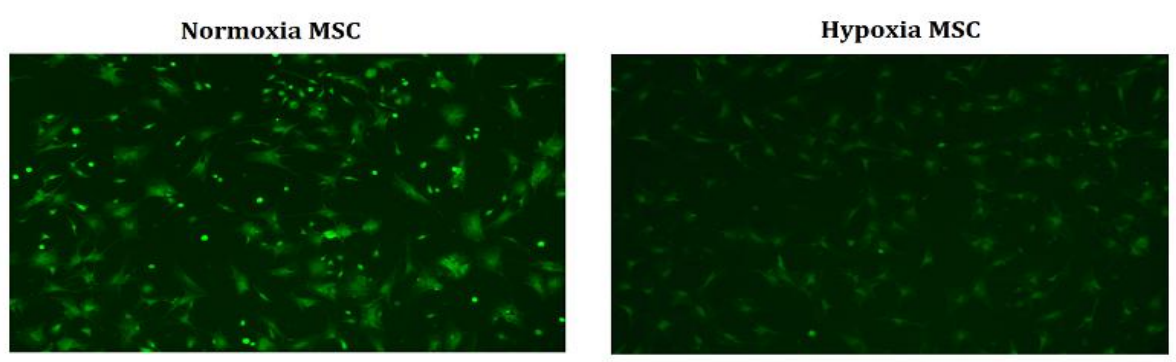

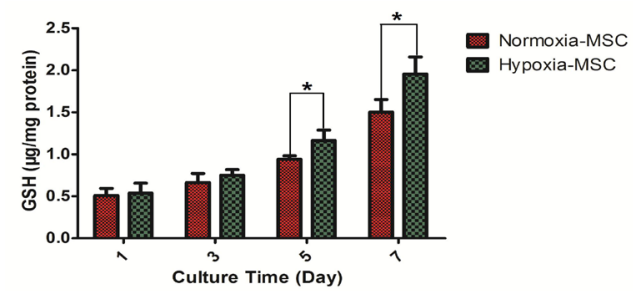

C

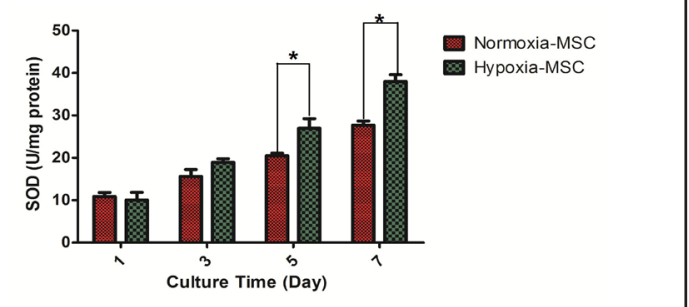

Fig. 5. Hypoxia MSCs have decreased ROS and increased antioxidant ability: Primary MSCs were divided to culture under normoxia and hypoxia conditions respectively, the level of ROS was detected on the seventh day by intracellular ROS fluorogenic probe staining (green). Higher intensity of fluorescence represented more ROS generation (A). The antioxidant ability was detected by measuring content of GSH and SOD on the first, third, fifth and seventh day (B, C). Magnification x 200. Data were presented as mean \pm SD $(n=3)$. ${ }^{*} \mathrm{P}<0.05$ as compared with control.

Fig. 6. Hypoxia MSCs acquired higher resistance to hypoxia and ROS stress than normoxia MSCs: Normoxia MSCs and hypoxia MSCs were primarily planked into 96 well plates with a concentration of $5 \times 10^{3}$ cells $/$ well. 12 hours later, all the MSCs were incubated under hypoxia condition $(1 \%$ $\mathrm{O}_{2}$ ) and the cells viability were determined by CCK8 assay at $1 \mathrm{~h}, 4 \mathrm{~h}, 8 \mathrm{~h}, 12 \mathrm{~h}$, $24 \mathrm{~h}$, respectively (A). Normoxia MSCs and hypoxia MSCs were treated with/ without $\mathrm{H}_{2} \mathrm{O}_{2}(100 \mu \mathrm{M})$ for $12 \mathrm{~h}$, and then all the MSCs were harvested to test apoptosis rate by flow cytometry (B). Data were presented as mean \pm SD (n $=3$ ). ${ }^{*} \mathrm{P}<0.05$ as normoxia MSCs $+\mathrm{H}_{2} \mathrm{O}_{2}$ group VS hypoxia MSCs $+\mathrm{H}_{2} \mathrm{O}_{2}$ group.
A

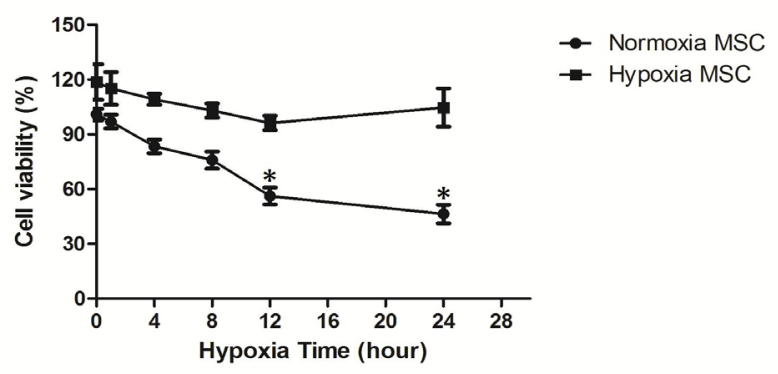

B
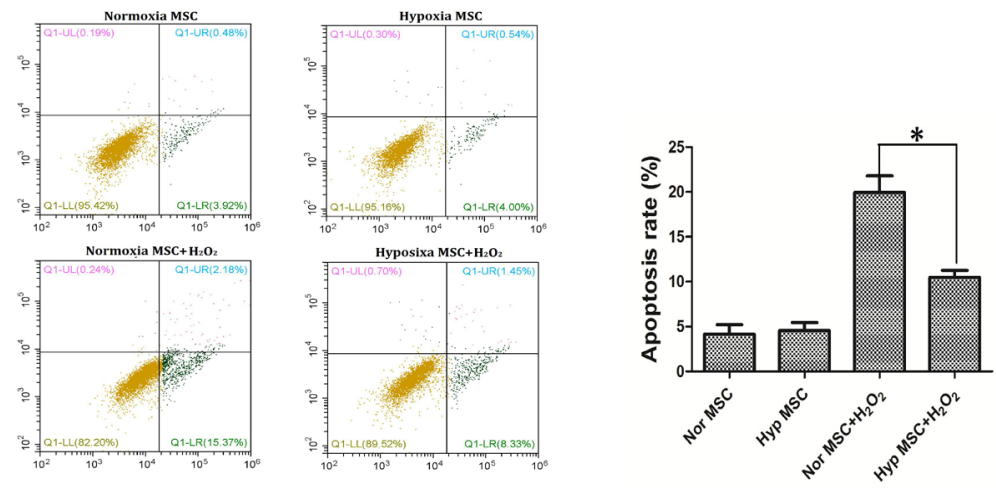
Fig. 7. Hif- $1 \alpha$ was involved in the resistance of hypoxia MSCs to hypoxia stress: Normoxia MSCs and Hypoxia MSCs were exposed to hypoxia condition $\left(1 \% \mathrm{O}_{2}\right)$, and MSCs were harvested to detect the expression of p-Akt (S473), Akt, Caspase-3, Hif-1 $\alpha$ at $1 \mathrm{~h}, 4 \mathrm{~h}, 8 \mathrm{~h}, 12 \mathrm{~h}$ respectively (A); quantitative analysis of both proteins were performed (B). 8 hours after hypoxia exposure $\left(1 \% \mathrm{O}_{2}\right)$ with/without 2-MeOE2 $(30 \mu \mathrm{M})$, normoxia MSCs and hypoxia MSCs were harvested to test the protein expression level of HIF$1 \alpha$, p-Akt (S473), Akt, Caspase-3 (C); quantitative analysis were performed (D). Hypoxia MSCs were planked into 96 well plates with the concentration of $5 \times 10^{3}$ cells/well. 12 hours later, hypoxia MSCs were exposed to hypoxia condition $\left(1 \% \mathrm{O}_{2}\right)$ with/without 2 -MeOE2 $(30 \mu \mathrm{M})$ and at $1 \mathrm{~h}, 4 \mathrm{~h}, 8 \mathrm{~h}$, $12 \mathrm{~h}, 24 \mathrm{~h}$ post-hypoxia cells viability were determined by CCK-8 assay (E). Data were presented as mean \pm SD $(\mathrm{n}=3)$. ${ }^{*} \mathrm{P}<0.05$ as hypoxia MSCs+2MeOE2 group VS hypoxia MSCs group at same time point.

MSCs had lower sensitivity to hypoxic stress. To verify the modulatory role of HIF-1 $\alpha$, 2-methoxyestradiol (2-MeOE2)an HIF-1 $\alpha$ inhibitor-was used. The results demonstrated that hypoxia $\left(\begin{array}{ll}1 \% & 0_{2}\end{array}\right)$ stimulation did not upregulate caspase-3 in hypoxia MSCs $(P>0.05)$, but the combination of hypoxia with 2-MeOE2 significantly elevated its expression $(P<0.05)$, which indicated the critical role of HIF$1 \alpha$ in enhancing the resistance to hypoxia stress in hypoxia MSCs. However, there was no association between 2-MeOE2 use and p-Akt/Akt activation in
A

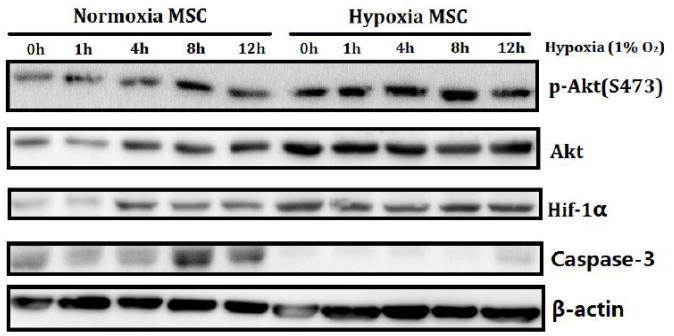

B
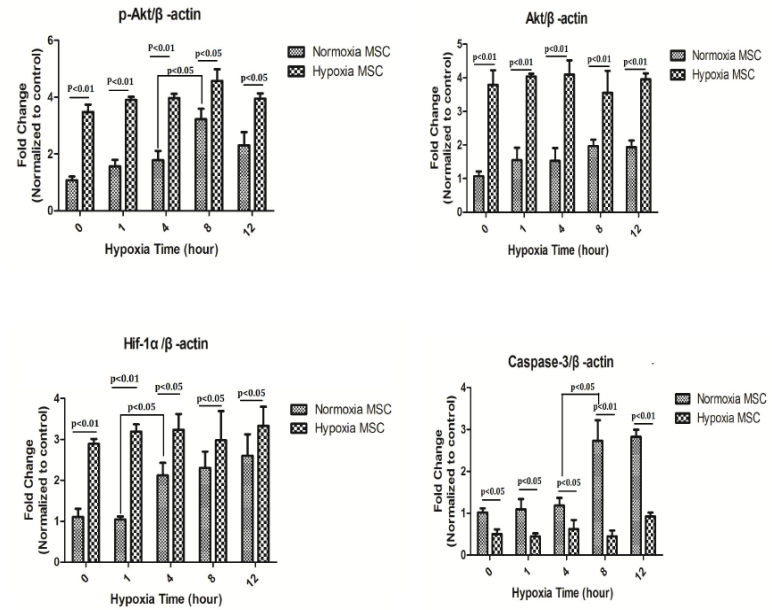

c

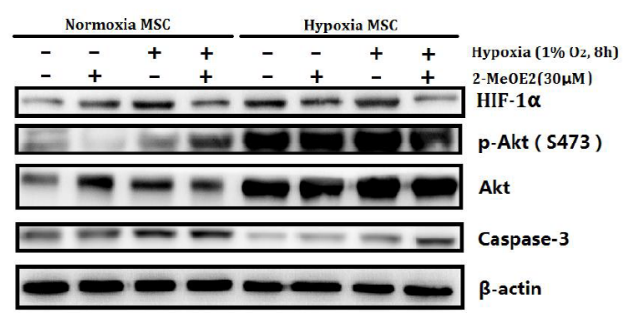

D
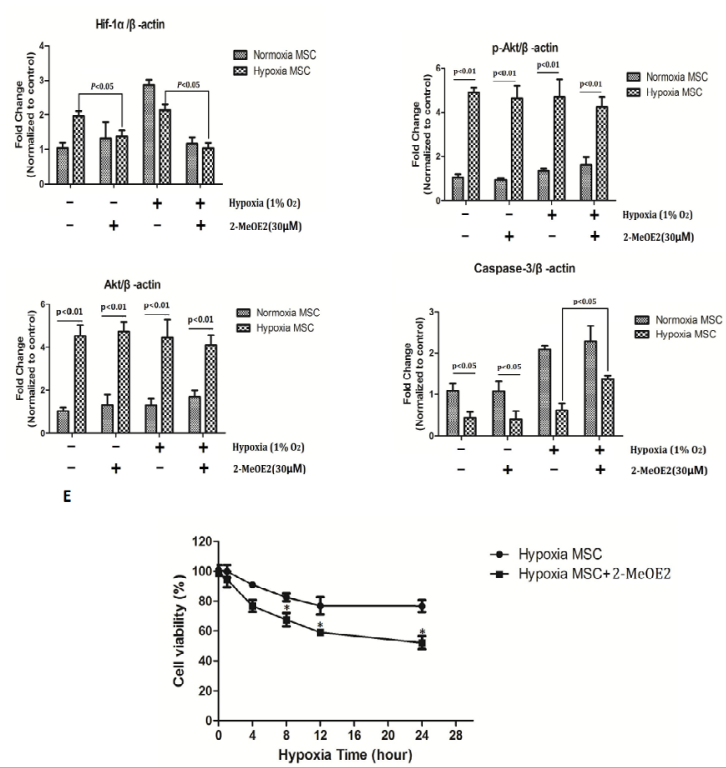

- Hypoxia MSC

- Hypoxia MSC+2-MeOE2 
Fig. 8. MSCs inhibited radiationinduced apoptosis in lung parenchymal cells: 3 days after radiation exposure, the mice lungs were taken to test histological apoptosis by TUNEL assay (A). MSCs and normal alveolar epithelial cells RLE-6TN were co-incubated for $24 \mathrm{~h}$ and $48 \mathrm{~h}$ after radiation exposure the apoptosis of RLE6TN cells were determined by flow cytometry (C). The quantitative analysis was performed (B, D). Data were presented as mean \pm SD ( $n=3)$.

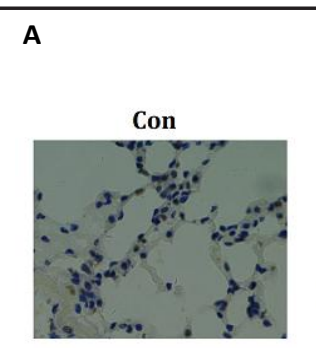

IR+Normixa MSC

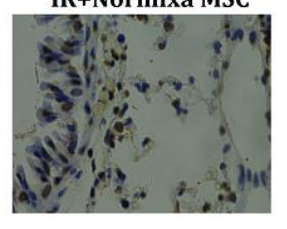

c

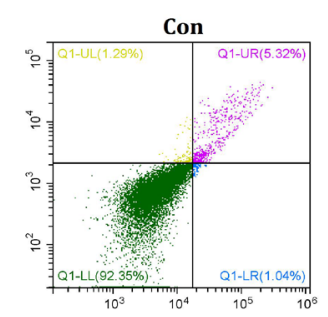

IR+Normoxia MSC

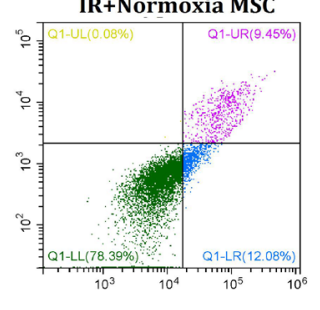

B

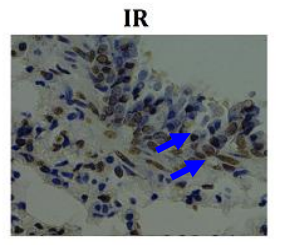

IR+Hypoxia MSC
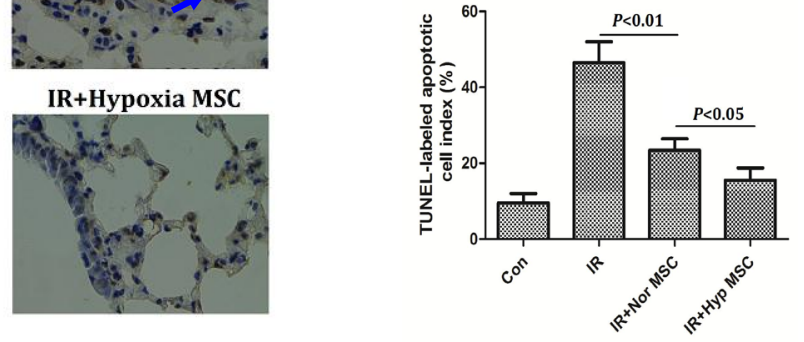

D
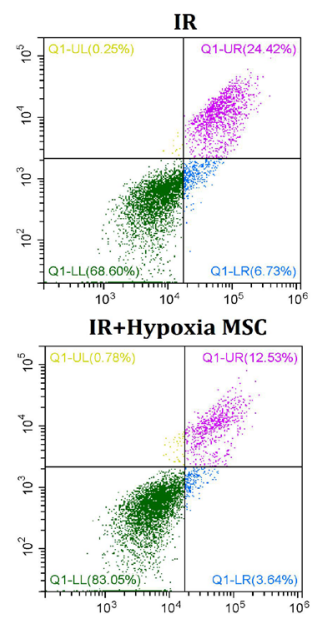

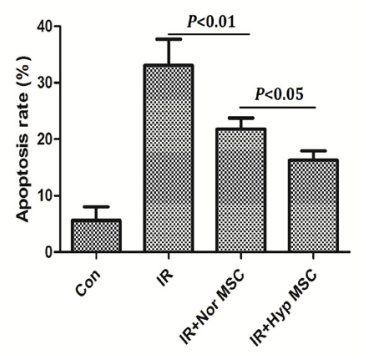

hypoxia MSCs (Fig. 7C, D). Finally, the effect of 2-MeOE2 on the viability of hypoxia MSCs was tested. As expected, 2-MeOE2-the inhibitor of HIF-1 $\alpha$-rendered hypoxia MSCs more susceptible to hypoxia stress (Fig. 7E).

\section{MSCs inhibited radiation-induced apoptosis in lung parenchymal cells}

Hypoxia MSCs were demonstrated to gain an enhanced capacity of survival in radiation-injured lungs. Next, we investigated whether the implanted MSCs affect lung parenchymal cells. Radiation primarily leads to cellular apoptosis, which is critical in development of RILI. Therefore, we evaluated the influence of MSC treatment on apoptosis. Three days after radiation, lungs were histologically examined using TUNEL staining to detect apoptosis. Results indicated that implanted MSCs reduced the numbers of TUNELlabeled lung parenchymal cells, including alveolar epithelial cells and bronchial epithelial cells. Furthermore, hypoxia MSCs exerted a greater anti-apoptotic effect compared to that of normoxia MSCs (Fig. 8A, B; TUNEL-labeled apoptotic cell index: $23.40 \pm 3.04 \%$ vs. $15.60 \pm 3.17 \%$, respectively $P<0.05$ ). Next, cellular experiments were conducted. First, MSCs were co-cultured with normal alveolar epithelial cells RLE-6TN for $24 \mathrm{~h}$. Next, apoptosis of RLE-6TN cells were evaluated $48 \mathrm{~h}$ after radiation. The results demonstrated that coincubation with MSCs reduced apoptosis rates of RLE-6TN cells. Treatment of hypoxia MSCs, as expected, rescued more radiated cells than did treatment with normoxia MSCs (Fig. 8C, D; apoptosis rate: $21.82 \pm 1.95 \%$ vs. $16.28 \pm 1.63 \%$, respectively; $P<0.05$ ). 


\section{Cellular Physiology Cell Physiol Biochem 2017;44:1295-1310

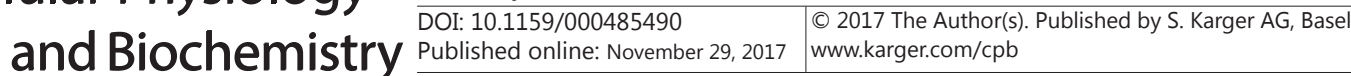

Li et al.: Hypoxia Enhances the Therapeutic Effect of Mscs on RILI

\section{Discussion}

MSCs have been reported to be an effective treatment for several diseases, such as ischemic heart failure [10], hind limb ischemia [11], and damage of the liver, skin and gut [1215]. Migration of implanted MSCs to the injury site is mediated by matrix metalloproteinases [26]. Retained MSCs play a role in damage repair by differentiating into different types of connective tissue [27], promoting angiogenesis [28] and exerting anti-inflammatory effect $[29,30]$. However, unlike the abovementioned injuries, RILI has received limited improvement from MSC treatment. The development of RILI is complex and polyfactorial, involving increased ROS and local hypoxia [31,32]. The hostile environment around injured lungs leads to poor survival and less retention of implanted MSCs [24]. Increased apoptosis rates of implanted MSCs, especially under hypoxic conditions, were observed [33], which explains the limited application of MSCs in the treatment of RILI.

Since the poor survival of MSCs is primarily due to hypoxia and generated ROS, we hypothesize that persistent and adaptive hypoxia treatment may enhance the resistance of implanted MSCs to hypoxia pressure. In agreement with Francois et al [34]., who demonstrated that MSCs produced Nrf2 which protected against injury by reducing ROS produced in the liver after radiation, MSCs receiving adaptive stimulation demonstrated an enhanced therapeutic effect.

We then investigated the therapeutic difference between normoxia and hypoxia MSCs in RILI. Primary mice MSCs from bone marrow were divided into two groups: one was cultured under normoxic condition, and the other was cultured under hypoxia. First, we identified the purity of MSCs. With persistent removal of suspension cells, we finally obtained pure MSCs (CD34- and CD45-negative). However, the hypoxia MSCs at the third passage revealed increased ratios of CD34-positive cells and decreased ratios of CD90-positive cells. It seemed that a differentiated diversity existed between the two groups. This result is in alignment with the study by Li Ni', which reported that hypoxia induced MSC differentiation [35]. It is commonly believed that changes in the surrounding environment of bone marrow may obviously influence the function and condition of bone marrow cells, which indeed includes MSCs and its differentiation. CD34 is considered an endothelial marker and CD90 is not expressed in murine hematopoietic cells. Compared to normoxia MSCs, the hypoxia MSCs demonstrated increased CD34 staining and decreased CD90 staining, indicating an acquisition of the endothelial phenotype in hypoxia MSCs and demonstrating that hypoxia may facilitate MSC differentiation.

Despite the differentiated diversity, hypoxia MSCs were more effective in treatment of RILI compared to normoxia MSCs, wherein the therapeutic effects included early remission of inflammation and terminal reduction of fibrosis. It is well known that fibrosis is the crucial process and primary obstacle for RILI treatment. To prevent fibrosis, long-term retention of MSCs and subsequent persistent action at the damaged site are necessary. In our study, the reduction of terminal fibrosis was evident in the hypoxia MSCs group. Hence, we speculated that the hypoxia-induced MSCs acquired enhanced survival in the inflammatory environment of radiation-induced lung injury. Next, a series of probative experiments on MSC survival was conducted. Cell viability was tested by the CCK-8 assay, and the results demonstrated that hypoxia-induced MSCs had increased cell viability compared to normoxia MSCs. To detect the potential for cell proliferation, we performed two classical studies: the clone formation assay and EdU detection. The results of the two experiments consistently confirmed increased proliferation of MSCs under hypoxic conditions. It is well-known that hypoxia promotes propagation of cancer cells and leads to resistance to radiotherapy and chemotherapy [36-38]. This process is commonly believed to be mediated by HIF-1 $\alpha$ activation and downstream signaling [39].

Another important factor that limits MSC retention in radiation-induced lung injury is the increased ROS level. In other words, implanted MSCs must overcome ROS stress in order to be persistently effective in RILI treatment. Since hypoxia MSCs demonstrated a long-term retention, we investigated whether the intracellular ROS levels and antioxidant ability were 
altered. The hypoxia MSCs demonstrated lower levels of ROS, as shown by labeling with specific ROS probes. On the other hand, increased levels of GSH and SOD, which are known as the most important intracellular antioxidants, were observed, suggesting that hypoxia induced an increase in antioxidant ability of MSCs. Previous studies have reported that MSCs have antioxidant capacity and therefore have a therapeutic effect on lung injury and fibrosis [40-42]. Our results not only confirmed this conclusion but also demonstrated a stronger antioxidant capacity in hypoxia-induced MSCs. These results may explain the reasons for the increased survivability of hypoxia MSCs in RILI. However, the hypothesis that hypoxia MSCs acquired resistance to hypoxia and ROS stress still need further confirmation. Comparison of cell viability between normoxia MSCs and hypoxia MSCs under hypoxia exposure $1 \%$ $\mathrm{O}_{2}$ ) demonstrated that hypoxia MSCs acquired a higher tolerance to hypoxia. After 12 hours of treatment with $\mathrm{H}_{2} \mathrm{O}_{2}$, normoxia MSCs demonstrated massive apoptosis $(20.17 \pm 4.15 \%)$, whereas hypoxia MSCs demonstrated a lower apoptosis rate $(12.23 \pm 2.64 \%)$. These results indicated that hypoxia MSCs acquired resistance to hypoxia and ROS stress.

Although several studies have confirmed that HIF-1 $\alpha$ is a critical regulator of cell hypoxic tolerance, its role in hypoxia-induced MSCs remains unclear. Thus, we investigated the expression of HIF- $1 \alpha$ in hypoxia MSCs. In addition, several survival pathway proteins, including p-Akt, Akt, caspase-3, were also detected. The results demonstrated that hypoxia MSCs acquired higher basic expression levels of p-Akt, Akt and HIF-1 $\alpha$ compared to those observed in normoxia MSCs. These results were consistent with previous reports, in which activation of Akt was observed when cells were exposed to hypoxia [43]. Akt and HIF-1 $\alpha$, as important pro-survival kinases, usually protect cells from various exogenous stresses. For MSCs, prolonged hypoxia stimulation resulted in a high levels and persistent activation of Akt and HIF-1 $\alpha$, which might have, in a way promoted the greater resistance to hypoxia and ROS stress demonstrated by hypoxia MSCs. However, we must note that although the inhibitor of HIF-1 $\alpha$ enhanced the sensitivity of hypoxia MSCs to hypoxic stress, the activation of Akt was not affected. Therefore, Akt and HIF-1 $\alpha$ exerted a protective effect in hypoxia MSCs, independently of each other.

In addition to investigating the proliferation and oxidation resistance of MSCs, we also explored the mechanism of MSC therapy. It is generally agreed that the mechanism of RILI includes radiation-induced injury of parenchymal cells [44], delayed activation of inflammatory reaction [45], and radiation-induced epithelial-mesenchymal transition (EMT) which is reported to mediate pulmonary fibrosis [46]. Therefore, the mechanism of MSC therapy for RILI is considered to regulate the inflammatory response [47-49] and the differentiation of damaged parenchymal cells to promote reconstruction [50]. Recently, some studies revealed the anti-apoptotic function of MSCs. As apoptosis is the early and direct effect of radiation on cells [51], we hypothesize that inhibition of apoptosis critically facilitates MSC therapy. Histological and cellular experiments demonstrated that the antiapoptotic effect was enhanced in hypoxia MSCs, which not only elevated resistance to the toxic environment but also increased anti-apoptotic ability, thereby rendering hypoxia MSCs more effective in RILI therapy.

There are some limitations of the present study. First, we demonstrated that the therapeutic effect of hypoxia MSCs on RILI is due to its increased survival rate and elevated resistance to ROS; however, the majority of the probative experiments were in vitro evaluations that failed to imitate the actual pathogenic process. Second, the improvement of survival and antioxidant ability of hypoxia MSCs has been confirmed; however, the molecular mechanisms underlying this improvement must be explored.

\section{Conclusion}

Long-term hypoxic conditions upregulate the expression of HIF-1 $\alpha$, induce increased survival and enhance the antioxidant ability of MSCs, thereby making them more effective in the treatment of RILI compared to normoxia MSCs. 


\section{Cellular Physiology Cell Physiol Biochem 2017;44:1295-1310

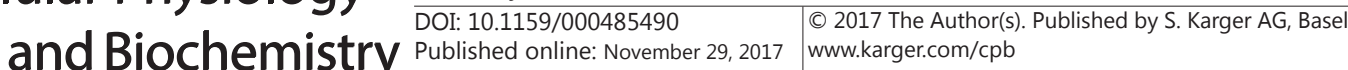

Li et al.: Hypoxia Enhances the Therapeutic Effect of Mscs on RILI

\section{Abbreviations}

RILI (Radiation-induced lung injury); MSCs (Mesenchymal stromal cells); ROS (reactive oxygen species).

\section{Acknowledgements}

This work was supported by the grants from National Natural Science Foundation of China (No. 81472911,31670861 and 11635014).

All data generated or analyzed during this study are included in this published article (and its supplementary information files).

All animal experiments conformed to the National Institute of Health 'Guide for the Care and Use of Laboratory Animals' (NIH Publication No. 85-23, National Academy Press, Washington, DC, revised 1996), with the approval of the Laboratory Animal Center of the Second Military Medical University, Shanghai. The approval ID for this study was 20101192.

\section{Disclosure Statement}

The authors declare that they have no competing interests.

\section{References}

1 Vujaskovic Z, Marks LB, Anscher MS: The physical parameters and molecularevents associated with radiation-induced lung toxicity. Semin Radiat Oncol 2000;10:296-307.

-2 Abratt RP, Morga GW: Lung toxicity following chest irradiation in patients with lung cancer. Lung Cancer 2002;35:103-109.

-3 Roach M, Gandara DR, Yuo HS, Swift PS, Kroll S,Shrieve DC, Wara WM, Margolis L, Phillips TL: Radiation pneumonitis following combined modality therapy for lung cancer: analysis of prognostic factors. J Clin Oncol 1995;39:553-559.

4 Usunier B, Benderitter M, Tamarat R, Chapel A: Management of fibrosis: the mesenchymal stromal cells breakthrough. Stem Cells Int 2014;2014:340257.

-5 Kwok E, Chan CK: Corticosteroids and azathioprine do not prevent radiation-induced lung injury. Can Respir J 1998;5:211-214.

6 Tuan RS, Boland G, Tuli R: Adult mesenchymal stem cells and cell-based tissue engineering. Arthritis Res Ther 200;5:32-45.

7 Romanov YA, Darevskaya AN, Merzlikina NV, Buravkova LB: Mesenchymal stem cells from human bone marrow and adipose tissue: isolation, characterization, and differentiation potentialities. Bull Exp Biol Med 2005;140:138-143.

-8 Pereira RF, Halford KW, O’Hara MD, Leeper DB, Sokolov BP, Pollard MD, Bagasra O, Prockop DJ: Cultured adherent cells from marrow can serve as long-lasting precursor cells for bone, cartilage, and lung in irradiated mice. Proc Natl Acad Sci USA 1995;92:4857-4861.

-9 Azizi SA, Stokes D, Augelli BJ, Digirolamo C, Prockop DJ: Engraftment and migration of human bone marrow stromal cells implanted in the brains of albino rats-similarities to astrocyte grafts. Proc Natl Acad Sci USA 1998;95:3908-3913.

10 Rosova I, Dao M, Capoccia B, Link D, Nolta JA: Hypoxic preconditioning results in increased motility and improved therapeutic potential of human mesenchymal stem cells. Stem Cells 2008;26:2173-2182.

11 Iwase T, Nagaya N, Fujii T, Itoh T, Murakami S, Matsumoto T, Kangawa K, Kitamura S: Comparison of angiogenic potency between mesenchymal stem cells and mononuclear cells in a rat model of hindlimb ischemia. Cardiovasc Res 2005;66:543-551. 


\section{Cellular Physiology Cell Physiol Biochem 2017;44:1295-1310 \\ \begin{tabular}{l|l} 
and Biochemistry Published online: November 29, 2017 & $\begin{array}{l}\text { (c) } 2017 \text { The Author(s). Published by S. Karger AG, Basel } \\
\text { www.karger.com/cpb }\end{array}$
\end{tabular}}

Li et al.: Hypoxia Enhances the Therapeutic Effect of Mscs on RILI

12 François S, Mouiseddine M, Mathieu N, Semont A, Monti P, Dudoignon N, Saché A, Boutarfa A, Thierry D, Gourmelon P, Chapel A: Human mesenchymal stem cells favour healing of the cutaneous radiation syndrome in a xenogenic transplant model. Ann Hematol 2007;86:1-8.

-13 Sémont A, Mouiseddine M, François A, Demarquay C, Mathieu N, Chapel A, Saché A, Thierry D, Laloi P, Gourmelon P: Mesenchymal stem cells improve small intestinal integrity through regulation of endogenous epithelial cellhomeostasis. Cell Death Differ 2010;17:952-961.

14 Sémont A, François S, Mouiseddine M, François A, Saché A, Frick J, Thierry D, Chapel A: Mesenchymal stem cells increase self-renewal of small intestinal epithelium and accelerate structuralrecovery after radiation injury. Adv Exp Med Biol 2006;585:19-30.

15 Mouiseddine M, François S, Souidi M, François A, Saché A, Frick J, Thierry D, Chapel A: Intravenous human mesenchymal stem cells transplantation in NOD/SCID mice preserve liver integrity ofirradiation damage. Methods Mol Biol 2012;826:179-188.

16 Xia C, Chang P, Zhang Y, Shi W, Liu B, Ding L, Liu M, Gao L, Dong L: Therapeutic effects of bone marrowderived mesenchymal stem cells on radiation-induced lung injury. Oncol Rep 2016;35:731-738.

17 Jiang X, Qu C, Chang P, Zhang C, Qu Y, Liu Y: Intravenous delivery of adipose-derived mesenchymal stromal cells attenuates acute radiation-induced lung injury in rats. Cytotherapy 2015;17:560-570.

18 Krause DS: Engraftment of bone marrow-derived epithelial cells. Ann N Y Acad Sci 2005;1044:117-124.

19 FENGYUN ZHANG, JINJIN CUI, BO LV, BO YU: Nicorandil protects mesenchymal stem cells against hypoxia and serum deprivation-induced apoptosis. Int J Mol Med 2015;36:415-423.

-20 Yazlovitskaya EM, Edwards E, Thotala D, Fu A, Osusky KL, Whetsell WO Jr, Boone B, Shinohara ET, Hallahan DE: Lithium treatment prevents neurocognitive deficit resulting from cranial Irradiation. Cancer Res 2006;23:11179-11186.

21 Huang Y, Liu W, Liu H, Yang Y, Cui J, Zhang P, Zhao H, He F, Cheng Y, Ni J, Cai J, Li B, Gao F: Grape seed proanthocyanidins ameliorates radiation-induced lung injury. J Cell Mol Med 2014;18:1267-1277.

-22 Zhao DY, Qu HJ, Guo JM, Zhao HN, Yang YY, Zhang P, Cao K, Lei X, Cui JG, Liu C, Cai JM, Gao F, Li BL: Protective Effects of Myrtol Standardized Against Radiation-Induced Lung Injury. Cell Physiol Biochem 2016;38:619634.

23 Dominici M, Le Blanc K, Mueller I, Slaper-Cortenbach I, Marini F, Krause D, Deans R, Keating A, Prockop Dj, Horwitz E: Minimal criteria for defining multipotent mesenchymal stromal cells. The International Society for Cellular Therapy position statement. Cytotherapy 2006;8:315-317.

24 Potier E, Ferreira E, Meunier A, Sedel L, Logeart-Avramoglou D, Petite H: Prolonged hypoxia concomitant with serum deprivation induces massive human mesenchymal stem cell death. Tissue Eng 2007;13:13251331.

25 Balamurugan K: HIF-1 at the crossroads of hypoxia, inflammation, and cancer. Int J Cancer 2016;138:105866.

-26 Hu C, Yong X, Li C, Lu M, Liu D, Chen L, Hu J, Teng M, Zhang D, Fan Y, Liang G: CXCL12/CXCR4 axis promotes mesenchymal stem cell mobilization to burn wounds and contributes to wound repair. J Surg Res 2013;183:427-434.

27 FFathke C, Wilson L, Hutter J, Kapoor V, Smith A, Hocking A, Isik F: Contribution of bone marrowderived cells to skin: collagen deposition and wound repair. Stem Cells 2004;22:812-822.

-28 Kinnaird T, Stabile E, Burnett MS, Lee CW, Barr S, Fuchs S, Epstein SE: Marrow-derived stromal cells express genes encoding a broad spectrum of arteriogenic cytokines and promote in vitro and in vivo arteriogenesis through paracrine mechanisms. Circ Res 2004 19;4:78-85.

29 S. Aggarwal and M. F: Pittenger. Human mesenchymal stem cells modulate allogeneic immune cell responses. Blood 2005;105:1815-1822.

-30 Nasef A, Mathieu N, Chapel A, Frick J, François S, Mazurier C, Boutarfa A, Bouchet S, Gorin NC, Thierry D, Fouillard L: Immunosuppressive effects of mesenchymal stem cells: involvement of HLA-G. Transplantation 2007;84:231-237.

-31 Robbins ME, Zhao W: Chronic oxidative stress and radiation-induced late normal tissue injury: a review. Int J Radiat Biol 2004;80:251-259.

32 Zhao W, Robbins ME: Inflammation and chronic oxidative stress in radiation-induced late normal tissue injury: therapeutic implications. Curr Med Chem 2009;16:130-143. 


\section{Cellular Physiology Cell Physiol Biochem 2017;44:1295-1310 \begin{tabular}{ll|l} 
DOI: 10,1159/000485490 & O 2017 The Author(s). Published by S. Karger AG, Basel \\
wwww.karger.com/cpb
\end{tabular}}

Li et al.: Hypoxia Enhances the Therapeutic Effect of Mscs on RILI

33 Zhu W, Chen J, Cong X, Hu S, Chen X: Hypoxia and serum deprivation-induced apoptosis in mesenchymal stem cells. Stem Cells 2006;24:416-425.

34 Francois S, Mouiseddine M, Allenet-Lepage B, Voswinkel J, Douay L, Benderitter M, Chapel A: Human mesenchymal stem cells provide protection against radiation-induced liver injury by antioxidativeprocess, vasculature protection, hepatocyte differentiation, and trophic effects. Biomed Res Int 2013;2013:151679.

- 35 Ni L, Liu X, Sochacki KR, Ebraheim M, Fahrenkopf M, Shi Q Liu J, Yang H: Effects of hypoxia on differentiation from human placenta-derived mesenchymal stem cells to nucleus pulposus-like cells. Spine J 2014:2451-2458.

-36 Ruan K, Song G, Ouyang G: Role of hypoxia in the hallmarks of human cancer. J Cell Biochem 2009;107:1053-1062.

-37 Heddleston JM, Li Z, Lathla JD: Hypoxia inducible factors in cancer stem cells. Br J Cancer 2010;102:789795.

38 Semenza GL: HIF-1: Mediator of physiological and pathophysiological responses to hypoxia. J Appl Physiol 2000;88:1474-1480.

-39 Unruh A, Ressel A, Mohamed HG, Johnson RS, Nadrowitz R, Richter E, Katschinski DM, Wenger RH: The hypoxia-inducible factor-1a is a negative factor for tumor therapy. Oncogene 2003;22:3213-3220.

-40 Chow K, Fessel JP, Kaoriihida S, Schmidt EP, Gaskill C, Alvarez D, Graham B, Harrison DG, Wagner DH, Jr., Nozik-Grayck E, West JD, Klemm DJ, Majka SM: Dysfunctional resident lung mesenchymal stem cells contribute to pulmonary microvascular remodeling. Pulm Circ 2013;3:31-49.

41 Klein D, Steens J, Wiesemann A, Schulz F, Kaschani F, Röck K, Yamaguchi M, Wirsdörfer F, Kaiser M, Fischer JW, Stuschke M, Jendrossek V: Mesenchymal Stem Cell Therapy Protects Lungs from RadiationInduced Endothelial Cell Loss by Restoring Superoxide Dismutase 1 Expression. Antioxid Redox Signal 2017;26;563-582.

42 Day BJ: Antioxidants as potential therapeutics for lung fibrosis: Antioxid Redox Signal 2008;10:355-370.

43 Stegeman H, Kaanders JH, Wheeler DL, van der Kogel AJ, Verheijen MM, Waaijer SJ, Iida M, Grénman R, Span PN, Bussink J: Activation of AKT by hypoxia: a potential target for hypoxic tumors of the head and neck. BMC Cancer 2012;12:463.

44 Trott KR, Herrmann T, Kasper M: Target cells in radiation pneumopathy. Int J Radiat Oncol Biol Phys 2004;58:463-469.

45 Rübe CE, Wilfert F, Uthe D, König J, Liu L, Schuck A, Willich N, Remberger K, Rübe C: Increased expression of pro-inflammatory cytokines as a cause of lung toxicity after combined treatment with gemcitabine and thoracic irradiation. Radiother Oncol 2004;72:231-241.

-46 Narang H, Kumar A, Bhat N, Pandey BN, Ghosh A: Effect of proton and gamma irradiation on human lung carcinoma cells: Gene expression, cell cycle, cell death, epithelial-mesenchymal transition and cancer-stem cell trait as biological end points. Mutat Res 2015;780:35-46.

47 Bustos ML, Huleihel L, Meyer EM, Donnenberg AD, Donnenberg VS, Sciurba JD, Mroz L, McVerry BJ, Ellis BM, Kaminski N, Rojas M: Lung injury by increasing interleukin (IL)-10 and IL-1 RN levels. Stem Cells Transl Med 2013;2:884-895.

48 Horton JA, Hudak KE, Chung EJ, White AO, Scroggins BT, Burkeen JF, Citrin DE: Mesenchymal stem cells inhibit cutaneous radiation- induced fibrosis by suppressing chronic inflammation. Stem Cells 2013;31:2231-2241.

49 Chen C, Akiyama K, Yamaza T, You YO, Xu X, Li B, Zhao Y, Shi S. Telomerase governs immunomodulatory properties of mesenchymal stem cells by regulating FAS ligand expression. EMBO Mol Med 2014;6:322334.

50 Antoniou KM, Papadaki HA, Soufla G, Kastrinaki MC, Damianaki A, Koutala H, Spandidos DA, Siafakas NM: Investigation of bone marrow mesenchymal stem cells (BM MSCs) involvement in idiopathic pulmonary fibrosis (IPF). Respir Med 2010;104:1535-1542.

-51 Hu S, Fu S, Xu X, Chen L, Xu J, Li B, Qu Y, Yu H, Lu S, Li W: The mechanism of radiosensitization by YM155, a novel small molecule inhibitor of survivin expression, is associated with DNA damage repair. Cell Physiol Biochem 2015;37:1219-1230. 